\title{
Obesity and Hypertension in Students of Jahangirnagar University: Alarming Issues
}

\author{
Sudip Paul, Md. Solayman, Puja Biswas, Moumoni Saha, Md. Sabir Hossain \\ Department of Biochemistry and Molecular Biology, Jahangirnagar University, Savar, Dhaka 1342, Bangladesh
}

\begin{tabular}{l}
\hline \hline Article Info \\
\hline Article history: \\
Received May 12, 2015 \\
Revised Jul 20, 2015 \\
Accepted Aug 26, 2015
\end{tabular}

\section{Keyword:}

Hypertension

Obesity

Prevalence

University students

\begin{abstract}
The prevalence of obesity and hypertension (HTN) in university students of Bangladesh has not reported yet. Considering the proper health maintenance of this population in mind, the study was aimed to determine the prevalence of obesity and HTN as well as relationship among them in the students of a residential university of Bangladesh, Jahangirnagar University. This descriptive cross sectional study included 500 randomly selected students (250 males and 250 females). Participants completed a questionnaire on physical activity, sedentary behaviour, dietary factors, smoking and family history of obesity, HTN, and coronary artery disease. Blood pressure and anthropometric parameters such as height, weight, waist and hip circumferences were measured following standard procedure. The Statistical analyses were performed using the software SPSS.The prevalence of overweight was $25 \%$ (31.1\% males, $15.6 \%$ females) and obesity $7.2 \%$ (9.4\% males, $4 \%$ females). Pre-HTN was found at $27.1 \%$ (38\% males, $11.2 \%$ females) and HTN at 2.2\% (3.3\% males, $0.4 \%$ females). A high rate of smoking, sedentary behavior, physical inactivity, excessive consumption of unhealthy food, and caffeine-rich drinks was also observed. Significant correlation was found between parameters of obesity and HTN. High prevalence of pre-HTN in males and central obesity in females were found which is immediately needed to control for better health maintenance of this population.
\end{abstract}

Copyright (C) 2015 Institute of Advanced Engineering and Science. All rights reserved.

\section{Corresponding Author:}

Sudip Paul,

Department of Biochemistry and Molecular Biology,

Jahangirnagar University,

Savar, Dhaka 1342, Bangladesh, Contact No.: +8801674389745.

E-mail: sudippaul.bcmb@gmail.com

\section{INTRODUCTION}

Both obesity and hypertension (HTN) are major global health problems and there is a plausible linear relationship between them. The association between obesity and HTN has been reviewed and indicated that excess weight gain accounts for $65-75 \%$ of the risk for essential HTN [1].

Obesity and HTN are major contributors to many other diseases that are burden globally. In the recent years obesity has become rampant and is recognized as a main causative factor for many metabolic disorders that may have a negative effect on health, leading to reduced life expectancy and/or increased health problems. According to the global assessment performed by World Health Organization (WHO) in 2005 there were about 1.6 billion overweight persons aged 15 years and above and among them at least 400 million were obese. In addition, WHO predicts that approximately 2.3 billion adults will be overweight and more than 700 million will be obese within 2015 [2]. In most of the Asian countries including Bangladesh the prevalence of obesity has increased many times than past few decades, though the degree varies from countries to countries [3]-[13]. In 1996 the National Nutrition Survey of Japan (NNS-J) reported the obese people had 3.4 fold higher chance of hypertension compared to the underweight individuals [13]. Association 
of obesity with diabetes mellitus and cardiovascular diseases (CVDs) in South East Asia and Western Pacific regions is found epidemically [3],[12].

HTN as well has become a significant problem in many developing countries like Bangladesh undergoing epidemiological transition [14]. It is estimated that 9.4 million deaths occur for hypertension and it's complications in every year [15]. It is observed that higher the blood pressure greater the chances of heart attack, heart failure, stroke, and kidney diseases [16]. There is a lack of representable data on the prevalence of hypertension in the Bangladeshi population. Though an analysis performed by Zaman et al. [17] on the prevalence of hypertension in the Bangladeshi adult population included studies from 1976 to 1994 and estimated the prevalence to be $11.3 \%$. A meta-analysis also reported the prevalence of hypertension in Bangladesh is about $13.5 \%$ [18]. In addition, some studies with small sample size were conducted [19]-[30], which illustrated different prevalence rates.

In Bangladesh, there are a number of studies conducting to determine the prevalence of obesity and hypertension among urban and rural populations, and school going children but no such study was performed in university students. University students are not only a valuable part of the society, but also a different class for transition between young and adult ages. Moreover in recent days a number of disease conditions including HTN and CAD have been observed in this subset of population which is very alarming and should require special attention. Therefore we focused on university students in the present study. To gain information about the prevalence of obesity and hypertension as well as correlation among them in adult students of Jahangirnagar University we explored the use of traditional and novel tools to measure most parameters for determining these abnormalities. This will help identify and control cardiovascular risk factors occurring at young age in Bangladesh.

\section{SUBJECTS AND METHODS}

This was a descriptive cross-sectional study which included a total of 500 randomly selected students (250 males, 250 females) of Jahngirnagar University, Savar, Dhaka, Bangladesh. All students aged 18-22 years enrolled at undergraduate and graduate programs of the university were eligible to participate in this study. The study protocol was approved by the Ethical Review Committee, Faculty of Biological Sciences, Jahangirnagar University. Informed consent forms were obtained from the participants after providing detailed information about the purpose and nature of the study.

\subsection{Data collection}

Data on age, gender, educational status, physical activity, sedentary behavior, dietary habits, smoking, sleep and study duration and family history of diabetes mellitus (DM), obesity, HTN, and coronary artery disease (CAD) were collected by interviewing participants. Physical activity measures included daily duration of walking and other sport activities. Sedentary lifestyle included daily time spent watching TV, surfing internet, or playing video games in computer. Students with at least one first-degree relative with DM, obesity, HTN, or CAD were considered to have positive family history for these conditions. Concerning dietary factors students were considered to be high consumers of fast food or caffeinated drinks, if they consumed more than three fast food meals per week or greater than three cups of caffeine-containing drinks (coffee, tea, cola, and energy drinks) per day, respectively. Most of these parameters were categorized as described elsewhere [31].

\subsection{Outcome measurements}

\subsubsection{BP measurement}

The measurement of BP was performed using a digital blood pressure monitor machine after the subject was rested for $5 \mathrm{~min}$ in the sitting position. BP was categorized based on the recommendations of the Seventh Report of the Joint National Committee of Prevention, Detection, Evaluation and Treatment of High BP (JNC VII). The classification of BP (expressed in $\mathrm{mmHg}$ ) for adults aged 18 years or older will be as follows [32]: Normal if systolic BP was lower than 120 and diastolic BP was lower than 80, pre- HTN if systolic BP was 120-139 and/or diastolic BP was 80-89, and HTN if systolic BP was $>140$ and/or diastolic BP was $>90$.

\subsubsection{Anthropometric measurements}

For the screening of overweight and obesity, with the subject standing and shoes and jacket removed, height was measured by Leicester Height Measure (to the nearest $0.005 \mathrm{~m}$ ). Weight was measured (to the nearest $0.1 \mathrm{Kg}$ ) by using a digital scale. BMI (expressed in $\mathrm{kg} / \mathrm{m}^{2}$ ) was calculated and categorized as follows: underweight $<18.5$; normal weight 18.5-24.9; overweight 25-29.9; and obese $>30$ [33]. 
The waist circumference was measured at the midpoint between the lower margin of the last palpable rib and the top of the iliac crest, using a stretch resistant tape that provides a constant $100 \mathrm{~g}$ tension. Hip circumference was measured around the widest portion of the buttocks, with the tape parallel to the floor. For both measurements, WHO protocol was followed. Waist-hip (W: H) ratio was obtained by dividing waist circumference by hip circumference. Abdominal obesity was defined as a W: $\mathrm{H}$ ratio above 0.90 for males and above 0.85 for females [34].

\subsection{Statistical analysis}

The data were analyzed using Statistical Package for Social Sciences (SPSS) version 13.0. Data were mostly shown as percentages. The correlation between obesity and HTN was exploited using Pearson's correlation analysis value $<0.05$ was considered as statistically significant.

\section{RESULTS}

\subsection{Central obesity is more prevalent in females}

Central obesity, as assessed by WHR was found to be more prevalent in female students than males. About $69 \%$ female students and $46 \%$ male students were diagnosed with central obesity, while others were categorized as normal.

\subsection{Students mostly carry normal weight}

BMI of all the study subjects was measured as the parameter to assess the status of generalized obesity in this sub-set of population. Both male and female students mostly belonged to the normal weight group at $76 \%$ and $70.8 \%$ respectively. In case of overweight, the percentages for males and females were $13.2 \%$ and $12 \%$ respectively. The percent of obesity assessed by BMI was $0.8 \%$ for males and $3.2 \%$ for females. The detailed data are presented in Table 1.

Table 1. Status of generalized obesity in the study subjects

\begin{tabular}{cccc}
\hline & Male (\%) & Female (\%) & Total (\%) \\
\hline Underweight & $10(25)$ & $14(35)$ & $12(60)$ \\
Normal weight & $76(190)$ & $70.8(177)$ & $73.4(367)$ \\
Overweight & $13.2(33)$ & $12(30)$ & $12.6(63)$ \\
Obese & $0.8(2)$ & $3.2(8)$ & $2(10)$ \\
\hline
\end{tabular}

\subsection{Males are mostly pre-hypertensive and females are normotensive}

The prevalence of HTN greatly varied in males and females of the study population. Half of the male students were found to be pre-hypertensive, followed by normotensive and hypertensive. The prevalence of HTN was just over $9 \%$ in male students, while only $2 \%$ of the females were categorized as HTN. The female students were mostly normotensive, followed by pre-hypertensive and hypertensive. The data are shown in Table 2.

Table 2. Status of blood pressure in the study subjects

\begin{tabular}{cccc}
\hline & Male (\%) & Female $(\%)$ & Total $(\%)$ \\
\hline Normotensive & $40.8(102)$ & $74.8(187)$ & $57.8(289)$ \\
Pre-hypertensive & $50.0(125)$ & $23.2(58)$ & $36.6(183)$ \\
Hypertensive & $9.2(23)$ & $2.0(5)$ & $5.6(28)$ \\
\hline
\end{tabular}

\subsection{Most males have family history of hypertension}

The data regarding family history of DM, obesity, HTN and CAD were recorded for both male and female students. Most of the female students answered negatively in these questions, while just over half of them responded that they have family history of HTN. However, most of the male students $(64.8 \%)$ said that they have family history of HTN. Moreover, 53.6\% males responded positively for the family history of DM. In case of family history of obesity and CAD, male students mostly replied negatively Table 3 . 
Table 3. Family history of diabetes mellitus, obesity, hypertension and coronary artery diseases in the study subjects

\begin{tabular}{lccc}
\hline \multicolumn{1}{c}{ Family history } & Male (\%) & Female (\%) & Total (\%) \\
\hline Diabetes mellitus & & & $41.8(291)$ \\
Yes & $53.6(134)$ & $30.0(75)$ & $58.2(209)$ \\
No & $46.4(116)$ & $70.0(175)$ & $22.8(114)$ \\
Obesity & $24.4(61)$ & $21.2(53)$ & $77.2(386)$ \\
Yes & $75.6(189)$ & $78.8(197)$ & $57.0(285)$ \\
No & & & $43.0(215)$ \\
Hypertension & $64.8(162)$ & $50.8(127)$ & $26.6(133)$ \\
Yes & $35.2(88)$ & $49.2(123)$ & $73.4(367)$ \\
No & & & $26.0(185)$ \\
Coronary artery diseases & $27.2(68)$ & $74.0(65)$ & \\
Yes & $72.8(182)$ & & \\
No & & & \\
\hline
\end{tabular}

\subsection{Male and female students vary in their lifestyle and dietary features}

All of the females included in this study were nonsmoker, but $28 \%$ of male students were smoker and $72 \%$ were nonsmoker. Interestingly the females consumed greater amount of fast-food than males. Both males and females typically take 1-2 cups caffeine-rich drinks per day. Females were found be more physically inactive than males, while about half of subjects in both groups were found to lead sedentary lifestyle. The sleep duration of both male and female student was mostly between 6 to 8 hours per day. The detailed data for the prevalence of associated factors of obesity and HTN were presented in Table 4.

Table 4. Prevalence of different dietary and lifestyle indicators in the study subjects

\begin{tabular}{lccc}
\hline & Male $(\%)$ & Female $(\%)$ & Total (\%) \\
\hline Smoking & & & \\
Yes & $28(70)$ & 0 & $14(70)$ \\
No & $72(180)$ & $100(250)$ & $86(430)$ \\
Fast-food consumption & & & \\
None & $50.8(127)$ & $26.8(67)$ & $38.8(194)$ \\
$1-2$ meals/week & $36(90)$ & $14.4(36)$ & $25.2(126)$ \\
$>3$ meals/week & $13.2(33)$ & $58.8(147)$ & $36(180)$ \\
Caffeine-rich drinks consumption & & & \\
None & $19.6(49)$ & $20.4(51)$ & $20(100)$ \\
$1-2$ cups/day & $69.6(174)$ & $76.4(191)$ & $73(365)$ \\
$3-4$ cups/day & $10.8(27)$ & $3.2(8)$ & $7(35)$ \\
Physical activity & & & \\
$<30$ min/day & $54.8(137)$ & $65.2(163)$ & $60(300)$ \\
$30-60$ min/day & $30(75)$ & $34.4(86)$ & $32.2(161)$ \\
$>60$ min/day & $15.2(38)$ & $0.4(1)$ & $7.8(39)$ \\
Sedentary lifestyle & & & \\
$<60$ min/day & $18.8(47)$ & $7.2(18)$ & $13(65)$ \\
$60-120$ min/day & $36.8(92)$ & $38(95)$ & $37.4(184)$ \\
$>120$ min/day & $44.4(111)$ & $54.8(137)$ & $49.6(248)$ \\
Sleep duration & & & \\
$<6$ hours/day & $4.8(12)$ & $4.4(11)$ & $4.6(23)$ \\
$6-8$ hours/day & $82.8(207)$ & $72.8(182)$ & $77.8(389)$ \\
$>8$ hours/day & $12.4(31)$ & $22.8(57)$ & $17.6(88)$ \\
\hline
\end{tabular}

\subsection{Central obesity, generalized obesity and blood pressure are positively correlated with each other}

We found that the parameters of central obesity, generalized obesity and blood pressure, i.e. WHR, BMI, SBP and DBP respectively showed significant positive correlation with each other when analyzed in total study subjects Table 5 . 
Table 5. Correlation between parameters of obesity and blood pressure in the study subjects

\begin{tabular}{lccccc}
\hline & & \multicolumn{2}{c}{$\begin{array}{c}\text { Body Mass } \\
\text { Index }\left(\mathrm{Kg} / \mathrm{m}^{2}\right)\end{array}$} & $\begin{array}{c}\text { Waist Hip } \\
\text { Ratio }\end{array}$ & $\begin{array}{c}\text { Systolic Blood } \\
\text { Pressure }(\mathrm{mm} / \mathrm{Hg})\end{array}$ \\
\hline Pressure $(\mathrm{mm} / \mathrm{Hg})$
\end{tabular}

$r$, Pearson correlation co-efficient; $p, P$ value

$* *$ Correlation is significant at the 0.01 level (2-tailed).

* Correlation is significant at the 0.05 level (2-tailed).

\section{DISCUSSION}

Obesity and HTN of different age groups have been studied extensively in many developed countries, while in Bangladesh studies or data related to obesity and HTN on adolescent and young adults are relatively limited. To our knowledge, this is the first such study conducted on university students of Bangladesh.

Our study was carried out to examine the prevalence of obesity and HTN with their risk factors as well as relationship between them in a residential university of Bangladesh. The findings showed an alarming rate of raised blood pressure (BP), increasing weight gain, increasing high rate of smoking (especially in male students), increasing fast food consumption (especially in female students), low physical activity, and sedentary behavior among students. Al-Hazzaa et al. [35] also reported similar results representing that maintaining inactive lifestyle and consumption of unhealthy food are common in adolescent students.

Yoshiike et al. [36] observed the prevalence of obesity on 20-24 years old Japanese University students and found the prevalence of obesity of approximately 13\% in males and 5\% in females. Yoshimura et al. [37] reported, based on a study of the records of annual health examination of university students that in their freshman year, $15.4 \%$ of males and $11.2 \%$ of females were obese, while in their senior year, $9.9 \%$ of males and $5.2 \%$ of females were obese. In our study, the proportions of obese subjects (BMI $\geq 30)$ were $0.8 \%$ in males and $3.2 \%$ in females. The proportions of obese subjects in our study were somewhat less than those reported in previous studies but higher proportions were overweight, $13.2 \%$ males and $12 \%$ females. In a study conducted in students of a Bangladeshi medical college, the prevalence of central abdominal obesity (assessed by WHR) was found to be $35.88 \%$ (28.40\% in males and $43.65 \%$ in females) [38]. The percentages were lower than ours but the females were still more suffered by obesity as found by ours. The overall percentage of generalized obesity $\left(\mathrm{BMI} \geq 25 \mathrm{~kg} / \mathrm{m}^{2}\right)$ was $20.82 \%$ in all subjects $(20.09 \%$ in males and $21.58 \%$ in females). Higher prevalence of obesity among females at undergraduate medical level was also reported in Bangladesh [39]. By contrast, Yasin et al. [31] reported the lower rate of obesity in girls (4\%) than boys $(9.4 \%)$ with an overall proportion of $7.2 \%$.

In case of the proportions of hypertension $(\geq 140 \mathrm{mmHg}$ for SBP and/or $\geq 90 \mathrm{mmHg}$ for DBP) in Japanese young students, Kawasaki et al. [40] reported that approximately $14 \%$ of the students at the annual regular health check at a certain university were hypertensive. The proportions of hypertension reported in the 2001 National Nutrition survey of Japan (NNS-J) were 2.2\% males and $0.7 \%$ females aged $15-19$ years and $11.5 \%$ of males and $1.0 \%$ of females aged 20-29 years[13]. In our study, the respective values were $9.2 \%$ males and $2.0 \%$ females. Although, the proportions of hypertension from our study were close to the previous studies but an alarming proportions (50.0\% males and $23.2 \%$ females) were pre-hypertensive. Our data demonstrated that around half of the male students and one quarter of the female students had pre-HTN whereas HTN was evident more significantly in male than females. Notably, we found that the majority of students who suffered from high BP actually had pre-HTN. Higher BP in males compared to females was also observed in a study conducted in Bangladeshi private medical students [39]. In a study conducted among the students of a central university in West Bank, around one quarter of the students had reported to be prehypertensive whereas HTN was evident in $2.2 \%$ with males being significantly more affected than females [31]. Similarly, Ortiz-Galeano et al. [41] reported a high rate of pre-HTN in young adults in Spain $24 \%$. These data emphasize the importance of BP screening for young adults to detect any increase in BP at an early age.

There are many reports that obesity are associated with hypertension in middle aged individuals [41]-[47], but there have been only a few reports on young adults. Yoshimara et al. [37] reported 45.6\% of all 
male obese university students and $21.7 \%$ of all male obese university students were hypertensive. From our study, we found a strong correlation between obesity and HTN. When we performed Pearson bivariate correlation analysis between WHR, BMI, SBP and DBP, a significant positive correlation was observed between all parameters. Number of reports have published showing association between hypertension and increased BMI or weight gain in middle aged individuals or various age group [42],[43],[47]. Miyazaki et al. [48] and Chei, Choy-Lye, et al. [49] concluded that the appearance of hypertension tended to increase obesity. The results from our study are consistent with those reported previously.

\section{CONCLUSIONS}

The study identifies that students of Jahangirnagr University are suffering from an increased prevalence of excessive weight gain and elevated BP. Obesity and HTN were also found to be correlated among this population. A high rate of smoking, sedentary behavior, physical inactivity, excessive consumption of unhealthy food, and caffeine-rich drinks was also observed. The findings put emphasis on the value of promoting active lifestyle, smoking cessation, and screening for obesity and HTN among university students to lead a healthy life as well as control disease related factors.

\section{ACKNOWLEDGEMENTS}

Authors greatly acknowledge the technical support provided by the Department of Biochemistry and Molecular Biology, Jahangirnagar University, Bangladesh.

\section{REFERENCES}

[1] Wofford M. R., Hall J. E., "Pathophysiology and treatment of obesity hypertension", Curr. Pharm., vol. 10, pp. 3621-37, 2004.

[2] WHO, "Obesity and Overweight", Fact Sheet No. 311. September 2006. Online document at: www. who. int/mediacentre/factsheets/fs311/en/index.html Accessed September 2010.

[3] Yoon K. H., Lee J. H., Kim J. W., Cho J. H., Choi Y. H., Ko S. H., et al., "Epidemic obesity and type 2 diabetes in Asia”, Lancet, vol. 368, pp. 1681-8, 2006.

[4] Flegal K. M., Carroll M. D., Ogden C. L., Curtin L. R., "Prevalence and trends in obesity among US adults, 19992008", JAMA, vol. 303, pp. 235-41, 2010.

[5] Griffiths P. L., Bentley M. E., "The nutrition transition is underway in India”, J Nutr, vol. 131, pp. 2692-700, 2001

[6] Sidik S. M., Rampal L., "The prevalence and factors associated with obesity among adult women in Selangor, Malaysia", Asia Pacific family medicine, vol. 8, pp. 1-6, 2009.

[7] Prentice A. M., "The emerging epidemic of obesity in developing countries", Int J Epidemiol, vol. 35, pp. 93-9, 2006.

[8] Ho C., Tsai A. C., "Prevalence of overweight and obesity and its associated factors in aboriginal Taiwanese: findings from the 2001 National Health Interview Survey in Taiwan”, Asia Pac J Clin Nutr, vol. 16, pp. 572, 2007.

[9] Deurenberg-Yap M, Chew Sk Fau - Lin VF, Lin Vf Fau - Tan BY, Tan By Fau - van Staveren WA, van Staveren Wa Fau - Deurenberg P, and Deurenberg P., "Relationships between indices of obesity and its co-morbidities in multi-ethnic Singapore", Int J Obes Relat Metab Disord, vol. 25, pp. 1554-62, 2001.

[10] Ko G., Wu M., Tang J., Wai H., Chan C., Chen R., "Body mass index profile in Hong Kong Chinese adults", Ann Acad Med Singapore, vol. 30, pp. 393-6, 2001.

[11] Aekplakorn W., Chaiyapong Y Fau - Neal B, Neal B Fau - Chariyalertsak S, Chariyalertsak S Fau - Kunanusont C, Kunanusont C Fau - Phoolcharoen W, Phoolcharoen W Fau - Suriyawongpaisal P, et al., "Prevalence and determinants of overweight and obesity in Thai adults: results of the Second National Health Examination Survey", J Med Assoc Thai, vol. 87, pp. 685-93, 2004.

[12] Unwin N., Gan D., Whiting D., "The IDF Diabetes Atlas: providing evidence, raising awareness and promoting action", Diabetes Res Clin Pract, vol. 87, pp. 2-3, 2010.

[13] Tokyo: Dai-ichiShuppan Publishing Co., "The State of National Nutrition in Japanese (The results of National Nutrition Survey, Japan in 1996) (in Japanese)”, National Institute of Health and Nutrition, 1998.

[14] World Health Organization, "Cardiovascular diseases in developing countries", World Health Stat Q, vol. 46, pp. 90-150, 1993.

[15] Lim S. S., Vos T., Flaxman A. D., Danaei G., Shibuya K., Adair-Rohani H., et al., "A comparative risk assessment of burden of disease and injury attributable to 67 risk factors and risk factor clusters in 21 regions, 1990-2010: a systematic analysis for the Global Burden of Disease Study 2010”, Lancet, vol. 380, pp. 2224-60, 2013.

[16] Chobanian A. V., Bakris G. L., Black H. R., Cushman W. C., Green L. A., Izzo Jr J. L., et al., "The seventh report of the joint national committee on prevention, detection, evaluation, and treatment of high blood pressure: the JNC 7 report", JAMA, vol. 289, pp. 2560-71, 2003.

[17] Zaman M., Rouf M., "Prevalence of hypertension in a Bangladeshi adult population", J Hum Hypertens, vol. 13, pp. 547-9, 1999. 
[18] Moniruzzamani A. T., Rahmani S., Acharyyai A., Islami F. A., Ahmedi M. M., Zamanii M. M., "Prevalence of hypertension among the Bangladeshi adult population: a meta-analysis", in Regional Health Forum, 2013.

[19] Sayeed M. A., Banu A., Khan A. R., Hussain M. Z., "Prevalence of diabetes and hypertension in a rural population of Bangladesh", Diabetes Care, vol. 18, pp. 555-8, 1995.

[20] Sayeed M. A., Banu A., Malek M., Khan A. A., "Blood pressure and coronary heart disease in NIDDM subjects at diagnosis: prevalence and risks in a Bangladeshi population”, Diabetes Res Clin Prac, vol. 39, pp. 147-55, 1998.

[21] Rahman M., Tondel M., Ahmad S. A., Chowdhury I. A., Faruquee M. H., Axelson O., "Hypertension and arsenic exposure in Bangladesh", Hypertension, vol. 33, pp. 74-8, 1999.

[22] Zaman M. M., Yoshiike N., Rouf M. A., Syeed M. H., Khan M. R. H., Haque S., et al., "Cardiovascular risk factors: distribution and prevalence in a rural population of Bangladesh", J Cardiovasc Risk, vol. 8, pp. 103-8, 2001.

[23] Group H. S., "Prevalence, awareness, treatment and control of hypertension among the elderly in Bangladesh and India: a multicentre study", Bulletin of the World health Organization, pp. 490, 2001.

[24] Sayeed M., Banu A., Haq J., Khanam P., Mahtab H., Azad K. A., "Prevalence of hypertension in Bangladesh: effect of socioeconomic risk factor on difference between rural and urban community", Bangladesh Med Res Counc Bull, vol. 28, pp. 7-18, 2002.

[25] Zaman M. M., Choudhury S. R., Ahmed J., Numan S. M., Islam M. S., Yoshiike N., "Non-biochemical risk factors for cardiovascular disease in general clinic-based rural population of Bangladesh", J Epidemiol, vol. 14, pp. 63-8, 2004.

[26] Sayeed M., Mahtab H., Khanam P., Begum R., Banu A., Azad Khan A., "Diabetes and hypertension in pregnancy in a rural community of Bangladesh: a population-based study", Diabet Med, vol. 22, pp. 1267-71, 2005.

[27] Chen Y., Factor-Litvak P., Howe G. R., Parvez F., Ahsan H., "Nutritional influence on risk of high blood pressure in Bangladesh: a population-based cross-sectional study", Am J Clin Nutr, vol. 84, pp. 1224-32, 2006.

[28] Zaman M. M., Ahmed J., Choudhury S. R., Numan S. M., Parvin K., Islam M. S., "Prevalence of ischemic heart disease in a rural population of Bangladesh", Indian Heart J, vol. 59, pp. 239-41, 2006.

[29] Van Minh H., Soonthornthada K., Ng N., Juvekar S., Razzaque A., Ashraf A., et al., "Blood pressure in adult rural INDEPTH population in Asia", Glob Health Action, vol. 2, 2009.

[30] Chen Y., Factor-Litvak P., Howe G. R., Graziano J. H., Brandt-Rauf P., Parvez F., et al., "Arsenic exposure from drinking water, dietary intakes of $\mathrm{B}$ vitamins and folate, and risk of high blood pressure in Bangladesh: a population-based, cross-sectional study", Am J Epidemiol, vol. 165, pp. 541-52, 2007.

[31] Tayem Y. I., Yaseen N. A., Khader W. T., Rajab L. O. A., Ramahi A. B., Saleh M. H., "Prevalence and risk factors of obesity and hypertension among students at a central university in the West Bank", Libyan J Med, vol. 7, 2012.

[32] Lenfant C., Chobanian A. V., Jones D. W., Roccella E. J., "Seventh report of the Joint National Committee on the Prevention, Detection, Evaluation, and Treatment of High Blood Pressure (JNC 7) resetting the hypertension sails", Circulation, vol. 107, pp. 2993-4, 2003.

[33] Tan K., "Appropriate body-mass index for Asian populations and its implications for policy and intervention strategies", Lancet, vol. 363, pp. 157-63, 2004.

[34] Consultation W. E., "Waist Circumference and Waist-Hip Ratio: Report of a WHO Expert Consultation", GENEVA, 8-11 DECEMBER 2008, 2011.

[35] Al-Hazzaa H. M., Abahussain N. A., Al-Sobayel H. I., Qahwaji D. M., Musaiger A. O., "Physical activity, sedentary behaviors and dietary habits among Saudi adolescents relative to age, gender and region", Int $J$ Behav Nutr Phys Act, vol. 8, pp. 140, 2011.

[36] Yoshiike N., Matsumura Y., Zaman M. M., Yamaguchi M., "Descriptive epidemiology of body mass index in Japanese adults in a representative sample from the National Nutrition Survey 1990-1994", Int. J. Obes., vol. 22, pp. 684-7, 1998.

[37] Yoshimura Y., Ishikawa C., Kamachi M., Tanaka K., Harano Y., "The first clinical picture of lifestyle-related diseases in university students: obesity and hypertension (in Japanese)", Campus Health, vol. 37, pp. 440-43, 2001.

[38] Sultana N., Nahar S., Debnath B. C., Rahman M. Z., Naher M., Malik S., "Prevalence of obesity among the medical students in Sylhet", Jalalabad Medical Journal, vol. 8, pp. 12-5, 2011.

[39] Yeasmin R., Choudhury S., Parveen S., Nahar N., Begum K., Akhter F., "Assessment of overweight, obesity and metabolic variables among students of a private medical college in Dhaka city", Bangladesh Journal of Medical Science, vol. 14, pp. 53-8, 2015.

[40] Kawasaki T., Uezono K., Sanefuji M., Utsunomiya H., Fujino T., Kanaya S., et al., “A 17-year follow-up study of hypertensive and normotensive male university students in Japan”, Hypertens Res, vol. 26, pp. 445-52, 2003.

[41] Ortiz-Galeano I., Franquelo-Morales P., Notario-Pacheco B., Nieto R. J., Ungría C. M., Martínez-Vizcaíno V., "Arterial pre-hypertension in young adults", Rev Clin Esp, vol. 212, pp. 287-91, 2012.

[42] Weatherall R., Shaper A., "Overweight and obesity in middle-aged British men”, Eur J Clin Nutr, vol. 42, pp. 221$31,1988$.

[43] Ko G., Chan J., Woo J., Lau E., Yeung V., Chow C., et al., "Simple anthropometric indexes and cardiovascular risk factors in Chinese", Int J Obes Relat Metab Disord, vol. 21, pp. 995-1001, 1997.

[44] Huang Z., Willett W. C., Manson J. E., Rosner B., Stampfer M. J., Speizer F. E., et al., "Body weight, weight change, and risk for hypertension in women", Ann Intern Med, vol. 128, pp. 81-8, 1998.

[45] Field A. E., Byers T., Hunter D. J., Laird N. M., Manson J. E., Williamson D. R., et al., "Weight cycling, weight gain, and risk of hypertension in women", Am J Epidemiol, vol. 150, pp. 573-9, 1999. 
[46] Lee J. S., Kawakubo K., "A useful index highly correlated with coronary risk factors for community based obesity screening", Japanese journal of public health, vol. 46, pp. 89-102, 1999.

[47] Nakanishi N., Nakamura K., Ichikawa S., Suzuki K., Tatara K., "Lifestyle and the development of hypertension: a 3-year follow-up study of middle-aged Japanese male office workers", Occup Med, vol. 49, pp. 109-14, 1999.

[48] Miyazaki M., Sato Y., Makabe K., Okiyama T., Uno Y., Chang H., "Relationship of obesity with morbidity rate in university students (in Japanese)", Campus Health, vol. 37, 2001.

[49] Chei C. L., Iso H., Yamagishi K., Tanigawa T., Cui R., Imano H., et al., "Body fat distribution and the risk of hypertension and diabetes among Japanese men and women", Hypertens Res, vol. 31, pp. 8, 2008

\section{BIOGRAPHIES OF AUTHORS}
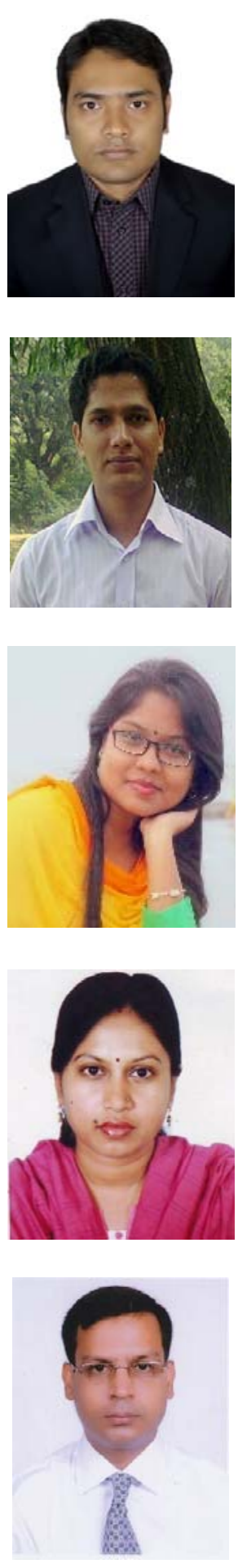

Sudip Paul is working as Lecturer in the Department of Biochemistry and Molecular Biology, Jahangirnagar University, Savar, Dhaka. He completed B.Sc (Hons.) and MS in Biochemistry and Molecular Biology from Jahangirnagar University, Bangladesh. His areas of research are Bioinformatics, Medicinal Chemistry, Molecular Pharmacology, Cancer Genetics and Public Health. E-mail: sudippaul.bcmb@gmail.com

Md. Solayman graduated from the Department of Biochemistry and Molecular Biology, Jahangirnagr University, Bangladesh. Currently, he is working on several research projects. He has excellent command over different bioinformatics tools. He is also working on Drug discovery and Computer Aided Drug Designing in Bangladesh Institute of Computational Chemistry and Biochemistry. His other research interests are clinical biochemistry, medicinal chemistry, medical genetics etc. E-mail: naeem40thju@gmail.com

Puja Biswasgraduated from the Department of Biochemistry and Molecular Biology, Jahangirnagr University, Bangladesh. Her scientific research interests are Clinical Biochemistry, Molecular Biology, Cancer Genetics etc. E-mail : biswas.puja@yahoo.com

MoumoniSaha completed her MS in Biochemistry and Molecular Biology from Jahangirnagar University, Bangladesh. Her scientific interests are: Molecular Pharmacology, Clinical Biochemistry, Medicinal Chemistry and Bioinformatics.

E-mail: moumonisaha@gmail.com

Md. Sabir Hossain is now working as Associate Professor in the Department of Biochemistry and Molecular Biology, Jahangirnagar University. He completed his $\mathrm{PhD}$ degree from Dhaka University. Apart from teaching different courses, he has conducted several research works on bioinformatics, nutrition and public health, clinical biochemistry etc.

E-mail: sabiriu@gmail.com 